\title{
A INFRAESTRUTURA TEXTUAL DO GÊNERO OMBUDSMAN: UM ESTUDO INTERACIONISTA SOCIODISCURSIVO
}

\author{
THE OMBUDSMN TEXT DESIGN: \\ A SOCIODISCOURSE INTERACTIONIST -BASED APPROACH
}

Daniela Zimmermann Machado

Doutoranda do Programa de Pós-graduação em Linguística - UFPR

Rodrigo Acosta Pereira

Doutorando do Programa de Pós-graduação em Linguística - UFSC

\section{Resumo}

O presente artigo objetiva investigar, sob o escopo do modelo interacionista sociodiscursivo (ISD) de análise de textos proposto por Bronckart (1997; 1999), a infraestrutura avaliativo-persuasiva do gênero ombudsman ${ }^{1}$. Para tanto, buscamos revisitar estudos de Bronckart (1997; 1999) e de Schneuwly e Dolz (2004), pesquisadores do grupo de estudos do ISD, e seus interlocutores no Brasil, Cristóvão (2001) e Machado (2005). Foram coletados dois exemplares do gênero, publicados nos sítios eletrônicos dos jornais Folha de SP (SP) e O Povo (CE) durante o mês de janeiro de 2009. Os resultados apresentam os tipos de discursos e de sequências textuais típicos do gênero, o discurso interativo e as sequências argumentativa e dialogal, respectivamente, e os mecanismos de textualização e de enunciação que se articulam na configuração textual do ombudsman.

Palavras-chave: Gênero ombudsman. Infraestrutura textual. Interacionismo sociodiscursivo (ISD).

\begin{abstract}
The present paper aims at investigating, through a sociodiscourse interactionist-based approach postulated by Bronckart $(1997 ; 1999)$, the ombudsman evaluative-persuasive text design. To do so, we reviewed theoretical studies from Bronckart (1997; 1999), Schneuwly \& Dolz (2004), Cristóvão (2001) and Machado (2005). Two instances of ombudsman genre were collected to develop the analysis from Folha de SP (SP) and $O$ Povo (CE) newspaper sites. The findings showed the typical discourse type - the interactive, the typical text sequences - argumentative and dialogic - and the typical text and enunciative mechanisms articulated in ombudsman genre.
\end{abstract}

Key-words: Ombudsman genre. Text design. Sociodiscourse interactionism.

\section{INTRODUÇÃO}

Como destacado na apresentação deste número da revista, o conjunto de trabalhos publicados analisa o mesmo gênero, o ombudsman, a partir de diferentes enfoques

\footnotetext{
${ }^{1}$ Cabe aqui ressaltar que usaremos a expressão ombudsman para nos referirmos ao gênero e Ombudsman ao autor do texto, o profissional que escreve a coluna no jornal.
} 
teóricos. Nessa perspectiva, a nossa análise tem por fundamento teórico o interacionismo sociodiscursivo (ISD).

O ISD compreende a relação entre a linguagem e a interação a partir de uma visão psicossocial, isto é, é uma perspectiva epistemológica que busca relacionar o quadro da psicologia da linguagem e da didática das línguas baseada nos estudos de pesquisadores da Unidade de Didática de Línguas da Faculdade de Psicologia e Ciências da Educação da Universidade de Genebra, especialmente por Bronckart, Schneuwly e Dolz ${ }^{2}$. Além disso, em investigações de cunho didático (por exemplo, pesquisas envolvendo processos pedagógicos e gêneros como objetos de ensino e aprendizagem), o ISD retoma Vygostky como fonte de referência; "[...] com uma abordagem marxiana, logo dialética, dos fenômenos psicológicos, esses autores colocam-se em favor da reunificação da psicologia, à qual atribuem uma dimensão social [...] (MACHADO, 2005, p. 238)”. Segundo Cristóvão (2001, p. 13-14),

O interacionismo sócio-discursivo é uma corrente da psicologia da linguagem que se apóia em uma perspectiva interacionista social de linguagem e em teorias de linguagem que dão primazia ao social, sobretudo na de Bakhtin (BRONCKART, 1997/1999). Seu quadro epistemológico se baseia na concepção de que 'as condutas humanas' são produto de um processo histórico de socialização, marcado, principalmente, pelo uso de instrumentos semióticos, como a linguagem. Os pressupostos do interacionismo sócio-discursivo que estaremos ressaltando serão os conceitos de aprendizagem e desenvolvimento de Vygostky (1934/1993) e suas decorrências para a prática do ensino de línguas.

No Brasil, o ISD tem apresentando crescente divulgação a partir do intercâmbio entre pesquisadores do país com o grupo de Genebra ${ }^{3}$. Os trabalhos, mesmo com diferenças visíveis e situadas, apresentam um traço em comum: a preocupação com a intervenção educacional e a atividade de formação. Com diferentes objetivos específicos, como as pesquisas com foco nas ferramentas de estudo, no aluno, na formação docente e na interação professor-ferramenta-aluno, diferentes conclusões e questionamentos ascendem e direcionam o ISD a uma contínua reflexão, especialmente ao que se refere ao modelo de análise de textos e de operações de linguagem (MACHADO, 2005). Desse modo, o presente estudo objetiva apresentar uma breve análise da infraestrutura textual do gênero ombudsman da esfera do jornalismo em ambiente virtual, buscando delinear as principais características linguístico-textuais desse gênero sob o escopo teórico-metodológico do ISD, a partir do modelo de análise de textos e de operações da linguagem proposto por Bronckart.

O trabalho apresenta-se assim organizado: (1) revisão de literatura visando a apresentar os fundamentos centrais da teoria do ISD; (2) metodologia buscando identificar as

\footnotetext{
${ }^{2}$ Como afirma Machado (2005, p. 237), "Embora os trabalhos dos três autores possam apresentar focos diferenciados, as teses globais e as que se referem a textos, gêneros de textos, tipos de textos, tipos de discurso e tipos de seqüência, assim como os elementos centrais do método de análise de textos, são por eles compartilhados."

${ }^{3}$ Um exemplo de programa de pós-graduação com relações interinstitucionais com o Grupo de Genebra é Programa de Estudos Pós-graduados em Linguística Aplicada e Estudos da Linguagem (LAEL), da PUCSP.
} 
etapas da pesquisa e (3) discussão dos dados, delineando os principais resultados da análise das regularidades linguístico-textuais do gênero ombudsman sob a perspectiva do ISD.

\section{REVISÃO DE LITERATURA}

Numa tentativa de refletir sobre a teoria do interacionismo sociodiscursivo e o estudo do gênero de texto, buscamos, através de uma análise teórica dos trabalhos de Bronckart (1997; 1999; 2004), Dolz e Schneuwly (2004), compreender melhor a perspectiva sociodiscursiva do tratamento da linguagem. Para isso, abordaremos a noção de atividade social e de ação de linguagem e a relação entre textos e gêneros de textos.

Antes, porém, faz-se necessário elucidar algumas considerações: é importante ressaltar que a tese desenvolvida por Bronckart $(1997$; 1999) sobre o ISD é validada/assumida, em adição, por Schneuwly e Dolz (2004), e que os três pesquisadores inserem-se na concepção do ISD. Dessa forma, embora compartilhem de algumas noções, Bronckart (1999) interessa-se por questões epistemológicas (comportamentais, do indivíduo), enquanto que Schneuwly e Dolz (2004) se voltam para o ensino do gênero de texto como ação social em sala de aula, preocupando-se, portanto, com o ensino. Como pontua Bronckart,

Adotando e desenvolvendo o pensamento vygotskyano, o interacionismo sociodiscursivo defende a tese de que o comportamento humano é o resultado de uma socialização particular capacitada por meio da emergência histórica de instrumentos semióticos (BRONCKART, 1997; 1999, p. 78).

\subsection{As atividades sociais e as práticas/ações de linguagem}

Trabalhar na perspectiva do ISD pressupõe, inicialmente, conhecimento de algumas das bases epistemológicas que contribuíram para o surgimento e a confirmação dessa perspectiva nos estudos da linguagem. Bronckart (1999) salienta que uma dessas bases é o trabalho de Vygostky ${ }^{4}$ (1984) sobre o interacionismo social, podendo ser considerado como precursor do ISD, devido à grande influência que exerceu sobre essa vertente.

A tese defendida por Vygostky (1984) é de que as propriedades específicas das condutas humanas são resultado de um processo histórico de socialização, que só foi possível pela emergência e pelo desenvolvimento da linguagem. A abordagem social, conforme Vygostky (1984), tem como objetivo:

Caracterizar os aspectos tipicamente humanos do comportamento das pessoas e elaborar hipóteses de como essas características se formaram ao longo da história humana e de como se desenvolvem durante a vida de um indivíduo. (VYGOTSKY, 1984, p. 21).

\footnotetext{
4 “A contribuição vygotskiana em diversas áreas do conhecimento é crescente no Brasil, com inúmeras pesquisas orientadas por seu pensamento. Dentre estas, no Brasil, salientamos os trabalhos de Oliveira (1993), de Wertsch \& Smolka (1994), de Rojo (1998), de Magalhães \& Rojo (1994), entre outras." (CRISTÓVÃO, 2001, p. 16).
} 
Assim, podemos caracterizar as investigações vigostkianas como históricas e sociais para com o tratamento da linguagem humana. O interacionismo social interessa-se, segundo Bronckart (1999), pelas condições que desenvolveram formas particulares de organização social, ao mesmo tempo ou sob o efeito do surgimento da linguagem.

Em segundo lugar, pressupõe o conhecimento e distinção entre os conceitos de atividade e ação, que, segundo Machado (2004), são essenciais para a compreensão do quadro geral do ISD. Esses conceitos provêm dos trabalhos de Leontiév (1984) e Habermas (1999), respectivamente, e também contribuíram para a consolidação da perspectiva teórica do interacionismo sociodiscursivo. Para tratar do conceito de atividade, Bronckart (1999) recupera as teorias de Leontiév (1984). Segundo este autor, atividade pode significar as organizações funcionais de comportamentos dos indivíduos, através das quais eles têm contato com o ambiente e podem adquirir conhecimento sobre este mesmo ambiente. A atividade sempre tem sua origem nas situações de comunicação, desenvolvendo-se em zonas de cooperação social determinadas. Podemos dizer que a atividade é o local, a situação de comunicação, envolvendo o coletivo. Segundo Machado (2004):

Cada atividade é constituída de ações, condutas que podem ser atribuídas a um agente particular, que são motivadas e orientadas por objetivos que implicam a representação e a antecipação de seus efeitos na atividade social. (MACHADO, 2004, p.23).

Por meio da citação, podemos inferir que há uma relação entre a atividade e a ação. Esses conceitos diferenciam-se, porém, compartilham de uma mesma situação, relacionando-se e possibilitando o estabelecimento de uma comunicação (linguagem). De forma simplificada, a atividade é o espaço onde a ação (o comportamento humano/ linguagem) acontece. Segundo Dolz e Schneuwly (2004, p 73), "a atividade pode ser também definida como um sistema de ações". Machado (2004) salienta ainda que as atividades são os determinantes primeiros da ação e do funcionamento psíquico humano e sustentam fundamentalmente nas atividades de linguagem. Seguindo Bronckart (1999),

É no contexto da atividade em funcionamento nas formações sociais que se constroem as ações imputáveis a agentes singulares e é no quadro estrutural das ações que se elaboram as capacidades mentais e a consciência desses mesmos agentes humanos. As condutas verbais são concebidas, portanto, como formas de ação (daí o termo ação de linguagem). (BRONCKART, 1999, p.13).

Em relação ao conceito de ação, como já dito, podemos destacar que Bronckart (1999) elege a ação da linguagem a partir dos estudos de Habermas (1999) sobre o agir comunicativo. $\mathrm{O}$ agir comunicativo refere-se à dimensão da forma como a atividade é caracterizada, uma vez que a cooperação dos indivíduos na sociedade é regulada e mediada por interações verbais. Essas interações são efetivadas no coletivo, na relação entre os indivíduos, e atuam em diferentes formas de representação, que Habermas (1999) denomina de mundos representados. Os mundos representados são formas a que os signos (linguagem comum) podem remeter e são em número de três: o mundo objetivo (ambiente físico), o mundo social (organização das tarefas) e o mundo subjetivo (autorreflexão, relação entre indivíduo e sua tarefa). 
Entendendo os mundos representados, vemos que eles contribuem para a compreensão do termo ação, pois é nessas três formas que as ações se constituem. É importante destacar que ao mudar o mundo objetivo, muda-se o mundo social e o subjetivo, modificando também a ação de linguagem atuante. Para Cristóvão (2001, p. 19),

[...] É nas atividades sociais em uma formação social que se desenvolvem as ações de linguagem. Diferentemente da concepção (aristotélica) de que as representações do mundo antecedem a linguagem, Bronckart (1997; 1999) considera como primeiras as dimensões históricas e sociossemióticas do funcionamento humano. Portanto, não são as capacidades cognitivas do sujeito o objeto primeiro de análise, pois o conhecimento é aprendido sempre em atividades coletivas sociais e mediatizadas por interações verbais. Assim, se o pensamento deriva da ação e da linguagem, o objeto de análise deve ser as ações de linguagem, relacionadas às representações do agente do contexto da ação, em seus aspectos físicos, sociais e subjetivos.

Podemos, dessa forma, compreender que a ação de linguagem integra os contextos de produção, circulação e recepção dos quais os sujeitos interlocutores participam. A partir dessa integração o sujeito mobiliza diferentes saberes de ordem cognitiva, linguística e social, dentre essas, a escolha do gênero adequado e significativo à situação na qual interage. É recorrendo ao repertório de gêneros disponível ao seu redor, que o sujeito interlocutor se apropria e relativamente estabiliza a situação de interação ${ }^{5}$.

Por exemplo, em uma palestra, a linguagem utilizada será mais formal, enquanto que em uma festa será mais informal, pois há uma diferença de comportamento (ações diferentes). Os mundos representados determinam a atividade e, conforme Schneuwly e Dolz (2004), os gêneros do discurso prefiguram as ações de linguagem possíveis em uma determinada atividade. Esses dois conceitos teóricos, ação e atividade, representam, na prática, a possibilidade de circulação dos gêneros. É com as ações humanas em atividade que os gêneros se desenvolvem.

\subsection{As relações constitutivas entre texto e gênero de texto para o ISD}

Revisitando as discussões teórico-metodológicas do ISD, podemos compreender que, para Bronckart (1999), "a noção de texto pode ser aplicada a toda e qualquer produção de linguagem situada, oral ou escrita" (BRONCKART, 1999, p.71). Assim, exemplos de textos seriam o diálogo familiar, um pedido de emprego, um romance etc. Bronckart (1999) destaca que:

Cada texto está em relação de interdependência com as propriedades do contexto em que é produzido; cada texto exibe um modo determinado de organização de seu conteúdo referencial. [...] Designa

\footnotetext{
${ }^{5}$ A ação de linguagem integraria os parâmetros do contexto de produção e do conteúdo temático que o agente-produtor de um texto mobiliza. A primeira dessas mobilizações é a escolha de um gênero que o agente considere adequado e eficaz para a situação que está vivendo. Para essa escolha, ele recorre ao conjunto de gêneros disponíveis ao seu redor e decide por aquele que se apresente como mais pertinente. (CRISTÓVÃO, 2001, p. 19).
} 
uma unidade concreta de produção de linguagem, que pertence necessariamente a um gênero, composta por vários tipos de discurso, e que também apresenta os traços das decisões tomadas pelo produtor individual em função da sua situação de comunicação particular. (BRONCKART, 1999, p. 71-77).

Vemos que as propriedades do contexto em que o texto é produzido mantêm relação com a ação de linguagem, com os mundos representados (HABERMAS, 1999), ou seja, o texto depende da ação que está sendo executada para ser caracterizado; de outra forma, os textos são produtos da atividade humana, estando articulados às necessidades sociais. Assim, podemos afirmar que texto, para o ISD, "é uma unidade comunicativa de nível superior" (BRONCKART, 1996, p. 74), ou seja, uma unidade de produção verbal, oral ou escrita, que veicula sentido para interlocutores em uma determinada situação de interação.

Os textos, sob esse panorama, passam a ser entendidos como ações sociais mediadas pela linguagem, não apenas significando as interações, como construindo e reconstruindo representações do mundo (representações do real). Em síntese, para o ISD, os textos são como unidades globais de significação, unidades de comunicação verbal, veiculadoras de sentido que, não apenas significam as práticas interativas, como, em adição, medeiam ações sociais e constroem e reconstroem representações da realidade (BRONCKART, 1996; 1999; HABERMAS, 1999).

Quanto aos gêneros textuais, Bronckart (1999) os define como reguladores e como produtos das atividades sociais de linguagem. Dessa forma, para o autor, nas diversas práticas interacionais, as ações de linguagem requerem do agente produtor uma série de decisões que ele precisa executar: a primeira delas é a escolha por um gênero existente, em que ele optará por aquele que lhe parecer adequado ao contexto e à intenção comunicativa; e a segunda é a aplicação, que poderá acrescentar algo à forma destacada ou recriá-la. Além disso, o autor pontua que:

A escolha do gênero deverá, portanto, levar em conta os objetivos visados, o lugar social e os papéis dos participantes. Além disso, o agente deverá adaptar o modelo do gênero a seus valores particulares, adotando um estilo próprio, ou mesmo contribuindo para a constante transformação dos modelos. (BRONCKART, 1994, p. 150).

Acerca da compreensão dos gêneros textuais sob a perspectiva do ISD, Machado (2005, p. 235 - 238) pontua que "o ISD não toma os gêneros de textos como unidade de análise privilegiada nem considera que sua análise seja seu objetivo maior". A autora destaca também que "[...] na verdade, não há um conceito de gênero que possamos atribuir de forma isolada a Bronckart". Segundo a autora, sempre que pensarmos em gênero, no sentido de Bronckart (1999), devemos fazer uma contextualização com a psicologia da linguagem e a didática das línguas, relacionando gêneros com atividades e ações sociais de linguagem.

Ainda a esse respeito, retomando Bronckart (1999, p. 138), "todo novo texto empírico [...] é necessariamente construído com base no modelo de um gênero, isto é, ele pertence a um gênero" e "mesmo sendo intuitivamente diferenciáveis, os gêneros não podem nunca ser objeto de uma classificação racional, estável e definitiva". Para o 
pesquisador, independentemente do gênero a que pertençam, os textos são constituídos por modalidades variáveis, ou seja, por segmentos de estatutos diferentes, e são esses segmentos que interessam a Bronckart. "E é unicamente no nível desses segmentos que podem ser identificadas regularidades de organização e de marcação lingüística" (BRONCKART, 1999, p.138).

Em adição às discussões anteriores, Bronckart (1996; 1999; 2001) investiga a questão dos gêneros textuais apresentarem-se como pré-construtos (construtos cognitivos) das ações sociais. Em outras palavras, o que o autor procura explicar é que os gêneros podem ser compreendidos como "modelos de referência" para as ações de um determinado estado sincrônico de uma sociedade. Os gêneros, para o autor, portanto, podem ser entendidos como reservatórios sócio-histórico-culturais de referenciais para as diversas ações e atividades sociais. Dessa forma, os gêneros não apenas estariam responsáveis pela significação de nossas ações, como também seriam os responsáveis pela regularização e referenciação dessas ações nas interações. Como bem esclarece Machado (2005, p. 250):

Portanto, os gêneros de textos constituem-se como pré-construtos, isto é, construtos existentes antes de nossas ações, necessários para sua realização. [...] eles são objetos de avaliações sociais permanentes, o que acaba por constituí-los, em um determinado estado sincrônico de uma sociedade, como uma espécie de reservatório de modelos de referência [...].

Outra questão central a ser discutida em adição às postulações anteriores sobre gêneros textuais, é a recorrente retomada dos estudos de Bakhtin e seu Círculo pelo ISD quanto às explicações deste sobre texto e gênero do discurso. Vários pesquisadores da ordem do ISD têm revisitado as discussões de Bakhtin sobre gêneros do discurso, tais como Bronckart (1997/1999), Schneuwly (1994), Dolz \& Schneuwly (1996 e 1998) e Machado (2000). Embora apoiados sob o conceito de 'gênero do discurso', conceito fiel ao pensamento bakhtiniano, o ISD tem o entendimento de que a definição de 'gênero textual' está mais próxima aos estudos interacionistas sociodiscursivos.

Em suma, podemos afirmar que os gêneros de textos, para o ISD, apresentam-se como ferramentas sociossemióticas que constroem e reconstroem configurações do mundo, do real (HABERMAS, 1999), medeiam situações sociais por meio da linguagem, são referenciais e modelos típicos de ações e atividades da linguagem, além de significarem e regularem nossas diferentes situações de interação. Assim, "a apropriação dos gêneros é, portanto, um mecanismo fundamental de socialização, de possibilidade de inserção prática dos indivíduos nas atividades comunicativas humanas" (MACHADO, 2005, p. 251). 


\section{METODOLOGIA}

Apresentaremos uma metodologia de trabalho que leve em conta as preocupações sociodiscursivas do ISD, ou seja, as intenções do autor do texto, o veículo de circulação, os propósitos e estratégias táticas (grau de formalidade). A partir desse quadro metodológico, analisaremos o nosso recorte de corpus, trabalhando com a proposta dos 3 níveis de análise do ISD, a nomear: o social, o linguístico-textual e o discurso. Sob essa perspectiva, focalizaremos neste presente estudo especificamente o nível linguístico-textual do gênero ombudsman, a partir de uma análise da sua construção avaliativo-argumentativa.

Selecionamos dois exemplares do gênero de texto para análise, cujos títulos são: "Quando é preciso chocar sem morbidez", de Carlos Eduardo Lins da Silva, Ombudsman do jornal Folha de S. Paulo, da cidade de São Paulo; e "Valeu à pena?" de Paulo Verlaine, Ombudsman do jornal $O$ Povo, da cidade de Fortaleza, publicados nos dias 04 e 03 de janeiro de 2009, respectivamente. Como já mencionado, faremos uma análise do gênero ombudsman, que se caracteriza pela autocrítica, e contemplaremos os seguintes níveis de análise: infraestrutura textual, construção linguístico-enunciativa e seus efeitos de sentido. Tal análise se valerá da teoria de Bronckart (1999) sobre o modelo de análise de textos para o ISD.

Investigaremos quais características presentes nos textos colocam o gênero inserido em um meio social e de interação. Lançamos a seguinte hipótese de trabalho: acreditamos que a forma como o texto caracterizado pelo gênero ombudsman se divide, ou melhor, se organiza, traz à tona a interação, um diálogo avaliativo-persuasivo, apresentando não apenas marcadores e construções textuais de avaliação, como, em adição, construções textuais persuasivas. Dessa forma, acreditamos que a sustentação da autocrítica requer um diálogo com o outro, este consubstanciando o teor avaliativo-argumentativo da textualidade do gênero ombudsman. Como já mencionado, para a análise, retomamos o modelo $^{6}$ de operações e níveis da linguagem proposto por Bronckart (1999) e revisitamos as considerações metodológicas de Machado (2005), abaixo propostas:

\footnotetext{
6 “Apesar de o modelo não ser concebido teoricamente para a descrição de gêneros, ele tem sido utilizado explícita ou implicitamente, quer para a descrição de algumas das características de gêneros particulares por pesquisadores ligados ao ISD (por exemplo, Schneuwly \& Dolz, 1998; Machado, 2000; Cristóvão, 2002; Coelho, 2003; Freitas 2003; Luca, 2000; Abreu, 2002; Lousada 2002), sobretudo com finalidades didáticas.” (MACHADO, 2005, p. 255).
} 
TABELA 1. Operações e níveis de análise de Bronckart

\begin{tabular}{|c|c|}
\hline Operações & Níveis da Análise \\
\hline $\begin{array}{l}\text { 1) Mobilização de representações sobre: } \\
\text { - contexto físico da ação; } \\
\text { - o contexto sociossubjetivo; } \\
\text { - conhecimento de mundo que podem ser verbalizados; } \\
\text { 2) Adoção do gênero. }\end{array}$ & $\begin{array}{l}\text { 1) Levantamento de hipóteses sobre as representações } \\
\text { do produtor: } \\
\text { - o contexto físico da ação; } \\
\text { - o contexto sociossubjetivo; } \\
\text { - conhecimentos de mundo que podem ser verbalizados; } \\
\text { 2) Levantamento de conhecimentos já construídos sobre } \\
\text { o gênero em questão. }\end{array}$ \\
\hline $\begin{array}{l}\text { 3) Gerenciamento da infraestrutura textual } \\
\text { 3.1) Escolha dos tipos de discurso; } \\
\text { 3.2) Seleção e organização global e local dos conteúdos. }\end{array}$ & $\begin{array}{l}\text { 3) Análise da infraestrtura textual } \\
\text { 3.1) Identificação dos tipos de discurso e de sua } \\
\text { articulação; } \\
\text { 3.2) Identificação do plano global do texto e dos tipos de } \\
\text { sequências; }\end{array}$ \\
\hline $\begin{array}{l}\text { 4) Textualização } \\
\text { 4.1) Estabelecimento de relações entre os segmentos, } \\
\text { enunciados, orações; } \\
\text { 4.2) Estabelecimento de um posicionamento } \\
\text { enunciativo: } \\
\text { - gerenciamento de vozes; } \\
\text { - expressão de modalizações; } \\
\text { 5) Construção de enunciados; } \\
\text { 6) Seleção de itens lexicais }\end{array}$ & $\begin{array}{l}\text { 4) Identificação dos mecanismos de textualização; } \\
\text { 4.1) da conexão e da coesão nominal e verbal; } \\
\text { 4.2) de mecanismos enunciativos: } \\
\text { - de inserção de vozes; } \\
\text {-das modalizações. }\end{array}$ \\
\hline
\end{tabular}

Fonte: Machado (2005, p. 254).

As categorias, operações e níveis descritos acima gerenciam a análise do gênero, não apenas apresentando etapas e procedimentos de investigação, como, em adição, demonstram sob quais parâmetros textuais o gênero se constrói e significa. A partir disso, apresentemos algumas considerações a respeito do modelo de análise de Bronckart (1999), delineando e explicando as categorias metodológicas contempladas para análise deste presente trabalho: a infraestrutura textual e a textualização (itens 3 e 4 do modelo de análise de Bronckart (1997; 1999)).

\subsection{A infraestrutura textual do gênero}

Com base nos estudos da arquitetônica textual desenvolvidos por Bronckart (1997; 1999), podemos afirmar que a infraestrutura textual dos gêneros é construída por meio da articulação de três planos ou dimensões textuais: o plano geral do texto, o tipo de discurso presente e o tipo de sequência.

\subsubsection{O plano geral do texto}

O plano geral do texto, segundo Bronckart (1997; 1999), se refere à organização do objeto temático no gênero. Essa dimensão do gênero depende, portanto, da temática (fatores próprios do conteúdo) e seu contexto de produção, circulação e recepção. Segundo Bronckart (1997; 1999, p. 248), "o plano geral de um texto é descrito, não com base em uma análise detalhada dos tipos de discurso e das diversas formas de planificação que ele combina, mas na forma de um resumo do conteúdo temático [...].” 


\subsubsection{Os tipos de discurso}

Os tipos de discurso são caracterizados e analisados pelo ISD a partir de uma ordem sociocognitivista. Cristóvão (2001, p. 61) assim explica a análise dessa dimensão da infraestrutura textual:

Para a distinção dos tipos de discurso, Bronckart (1997/1999) se baseia na descrição dos mundos $^{7}$ e nas operações psicológicas subjacentes à produção textual, bem como na descrição das configurações de unidades lingüísticas que caracterizam determinados segmentos do texto. Os mundos representados dos agentes são chamados de mundo ordinário (que reúne os três mundos representados: mundo objetivo, mundo social e mundo subjetivo) e os mundos discursivos, aqueles criados pela atividade de linguagem. Para a constituição dos mundos discursivos, dois conjuntos de operações se realizam.

$\mathrm{O}$ primeiro conjunto se refere à relação entre a organização do conteúdo temático com as coordenadas do mundo ordinário em que uma ação de linguagem acontece. $\mathrm{O}$ outro concerne à relação entre a agentividade e sua inscrição espaço-temporal no texto, bem como à relação com os parâmetros físicos da ação de linguagem.

A partir dessa explicação de Cristóvão (2001, p. 62), podemos verificar que há mundos discursivos relacionados a tipos de discurso, isto é, "a identificação das operações que constituem esses mundos é possível por meio de análise das formas lingüísticas típicas de cada mundo construído e que variam de acordo com a língua que veicula o texto." Dessa forma, podemos esquematizar da seguinte maneira os tipos de discurso e seus mundos de representação: mundos $^{8}$ da ordem do narrar (fatos abordados à distância da situação de interação) e mundos da ordem do expor (representações de origem conjunta à situação de interação) ${ }^{9}$.

TABELA 2. Tipos de discurso

\begin{tabular}{|l|l|l|}
\hline \multirow{2}{*}{ Relação à situação de produção } & \multicolumn{2}{|c|}{ Relação ao conteúdo } \\
\cline { 2 - 3 } & Eixo do Expor & Eixo do Narrar \\
\hline Implicação & Discurso Interativo & Relato Interativo \\
\hline Autonomia & Discurso Teórico & Narração \\
\hline
\end{tabular}

Fonte: Cristóvão (2001).

Podemos compreender, dessa forma, que para o entendimento dos tipos de discurso que se constroem na dimensão da infraestrutura textual do gênero é preciso, primeiramente, investigar a descrição de mundos (representações do real, conforme Habermas (1999)) e as operações psicológicas que se articulam na produção do texto para, posteriormente, buscar compreender os recursos linguísticos (gramaticais e lexicais) que caracterizam determinados segmentos da dimensão textual do gênero. Em síntese, podemos perceber que os tipos de discurso, nos diferentes segmentos de textos, em determinados gêneros,

\footnotetext{
${ }^{7}$ Baseado em Habermas (1999).

${ }^{8}$ Conforme Habermas (1999).

${ }^{9}$ Para maior esclarecimento retomar estudo de Cristóvão (2001).
} 
são constituídos de diferentes elementos linguísticos, que, articulados, estabelecem os sentidos e os efeitos de sentido da infraestrutura textual desse gênero ${ }^{10}$.

\subsubsection{Os tipos de sequências textuais}

Em adição aos tipos de discurso, a infraestrutura textual do gênero, para o ISD, é construída por tipos de sequências de texto que, assim como os tipos de discurso, organizam o conteúdo temático do gênero.

Bronckart (1999) recorre a Adam (1999) para sistematizar explicações quanto à organização e o funcionamento das sequências textuais na infraestrutura do gênero. Apresentando uma releitura crítica das proposições de Adam, assim esclarece Bronckart (1999, p. 218): "as seqüências são unidades estruturais relativamente autônomas que integram e organizam macroproposições, que, por sua vez, combinam diversas proposições, podendo a organização linear do texto ser concebida como o produto da combinação e da articulação de diferentes tipos de seqüências."

Em síntese, podemos entender que as sequências de texto nos gêneros funcionam como recursos organizadores do conteúdo temático na infraestrutura, isto é, modelos de planificação (CRISTÓVÃO, 2001), que se caracterizam linguisticamente em cinco tipos básicos, a citar: sequência narrativa, descritiva, argumentativa, explicativa e dialogal (ADAM, 1999; 2001).

Além disso, entendemos que o tipo de sequência usado em um texto está diretamente relacionado à sua função em um determinado gênero. Abaixo retomamos o quadro explicativo acerca das sequências textuais proposto por Cristóvão (2001, p. 66-67) para a compreensão do funcionamento dessas nos gêneros textuais.

\footnotetext{
10 Concordamos com Cristóvão (2001, p. 63), quando a autora explica que, “cabe aqui ressaltar uma diferença com abordagens que adotem uma perspectiva metodológica de análise do texto e de suas unidades sem relação com o contexto, caracterizando a produção como um produto lingüístico. $\mathrm{O}$ procedimento que defendemos estuda a organização e funcionamento dos textos nas situações de produção. A configuração dessas unidades tem um valor discriminativo, já que serão responsáveis pelo reconhecimento e diferenciação entre os tipos. Por isso, unidades como substantivos, verbos, adjetivos e outros, não são normalmente considerados, pois são comuns a vários discursos. Assim, estuda-se a ocorrência de uma determinada unidade, ou por ser exclusiva a um tipo de discurso, ou por sua ocorrência ter um valor estatisticamente significativo (BRONCKART, 1999, p. 165-6).”.
} 
TABELA 3. Tipos de sequências textuais

\begin{tabular}{|c|c|}
\hline $\mathrm{SE}$ & SEQUÊN \\
\hline $\begin{array}{l}\text { Ela é sustentada por um processo com início, meio e } \\
\text { fim, com ordem obrigatória. A situação mobiliza } \\
\text { personagens implicados em acontecimentos. Diante de } \\
\text { tensões na história, transformações vão acontecendo } \\
\text { fazendo-se necessário que o leitor/interlocutor acione } \\
\text { uma dimensão interpretativa. O protótipo mínimo seria } \\
\text { uma situação inicial (início), uma transformação (meio) } \\
\text { e uma situação final (fim). O protótipo padrão seria: } \\
\text { - fase de situação inicial: apresentação de um 'estado de } \\
\text { coisas'; } \\
\text { - fase da complicação: criação de perturbação e tensão; } \\
\text { - fase de ações: acontecimentos originados pela tensão; } \\
\text { - fase da resolução: redução da tensão; } \\
\text { - fase da situação final: apresentação de um novo estado } \\
\text { de equilíbrio por esta resolução. } \\
\text { Há também duas fases facultativas: } \\
\text { - fase de avaliação: comentário relativo ao desenrolar da } \\
\text { história; } \\
\text { - fase de moral: explicitação da significação } \\
\text { global . }\end{array}$ & $\begin{array}{l}\text { Ela é constituída por fases sem uma organização de } \\
\text { ordem linear obrigatória, porém com uma ordem } \\
\text { hierárquica ou vertical. Tais fases seriam: } \\
\text { - fase de ancoragem: o tema da descrição é } \\
\text { assinalado por, geralmente, um tema-título, } \\
\text { frequentemente, introduzido no início da sequência. } \\
\text { - fase de aspectualização: enumeração dos diversos } \\
\text { aspectos do tema-título. O tema é decomposto em } \\
\text { partes, às quais são atribuídas propriedades. } \\
\text { - fase de relacionamento: assimilação dos elementos } \\
\text { descritos por comparação ou metáforas. Uma simples } \\
\text { enumeração das partes é chamada de grau zero da } \\
\text { descrição. Os segmentos chamados de injuntivos, de } \\
\text { pragmáticos ou de instrucionais são organizados de } \\
\text { acordo com as mesmas fases, mesmo quando esta } \\
\text { organização se refere preferencialmente a ações e não a } \\
\text { objetos - descrição de ações. }\end{array}$ \\
\hline SEQUÊNCIA & SEQUENCI \\
\hline $\begin{array}{l}\text { São esquematizações de objetos de discurso, atestáveis } \\
\text { empiricamente em textos. As operações cognitivas } \\
\text { estariam relacionadas à existência de uma tese sobre um } \\
\text { tema, a entrada de novos dados a essa tese anterior, um } \\
\text { processo de inferência e uma conclusão ou nova tese. } \\
\text { Baseado nisso, normalmente essa sequência apresenta } \\
\text { quatro fases: } \\
\text { - fase de premissas: uma constatação de partida; } \\
\text { - fase de apresentação de argumentos: elementos que } \\
\text { orientam para uma conclusão provável; } \\
\text { - fase de apresentação dos contra-argumentos: elementos } \\
\text { que apresentam restrições à orientação dada; } \\
\text { - fase de conclusão: integração dos efeitos dos } \\
\text { argumentos e contra-argumentos. }\end{array}$ & $\begin{array}{l}\text { Ela se origina na constatação de um fenômeno } \\
\text { incontestável, mas que requer uma explicação das } \\
\text { causas e/ou razões da afirmação inicial, o que } \\
\text { reformulará a constatação inicial. Normalmente, este } \\
\text { protótipo tem quatro fases: } \\
\text { - fase de constatação inicial: introdução de um } \\
\text { fenômeno não contestável; } \\
\text { - fase de problematização: questionamento do porquê ou } \\
\text { do como, eventualmente, relacionado a uma contradição } \\
\text { aparente; } \\
\text { - fase de resolução: introdução de elementos que } \\
\text { respondam aos questionamentos; } \\
\text { - fase de conclusão-avaliação: reformula e completa a } \\
\text { constatação inicial. }\end{array}$ \\
\hline SEQUÊNCIA & FORMAS DE PLANIFICAÇÃO \\
\hline $\begin{array}{l}\text { Os interlocutores estão envolvidos em uma determinada } \\
\text { interação verbal na qual trocam enunciados que são } \\
\text { mutuamente determinados para formar um texto } \\
\text { coerente. As fases seriam: } \\
\text { - fase de abertura: os interactantes entram em contato; } \\
\text { - fase transacional: o conteúdo temático é coconstruído; } \\
\text { - fase de encerramento: fim da interação; } \\
\text { As fases são decompostas em trocas compostas de } \\
\text { intervenções (turnos de fala) e, em um outro nível, } \\
\text { decompostas em enunciados que realizam um ato de } \\
\text { fala. }\end{array}$ & $\begin{array}{l}\text { As sequências são uma reorganização de um conteúdo } \\
\text { temático já existente e manifestado a partir das } \\
\text { representações que se tem dos destinatários de seu texto, } \\
\text { e do efeito que se quer causar. } \\
\text { As sequências não se baseiam nas mesmas operações } \\
\text { que formam os tipos de discurso. Por isso se explica o } \\
\text { fato de um conteúdo temático poder ser organizado por } \\
\text { diferentes formas de planificação. } \\
\text { A ordem cronológica no domínio da ordem do } \\
\text { NARRAR é geralmente chamada de SCRIPT (grau zero } \\
\text { da planificação dos segmentos da ordem do narrar). } \\
\text { Nos segmentos da ordem do EXPOR, às vezes temos } \\
\text { textos simplesmente informativos ou expositivos (não } \\
\text { contestáveis, não problemáticos). } \\
\text { Sua forma de organização é chamada } \\
\text { ESQUEMATIZAÇÃO (grau zero da planificação dos } \\
\text { segmentos da ordem do expor). }\end{array}$ \\
\hline
\end{tabular}

Fonte: Cristóvão (2001, p. 66-67). 
Assim, como já mencionado anteriormente, a sequência textual está a serviço da função do gênero, portanto cada gênero textual é caracterizado por uma sequência ou sequências, que não apenas organizam o conteúdo temático desse gênero, como também o significam nas práticas de interação.

Após a breve explanação sobre as categorias de análise da infraestrutura textual dos gêneros, direcionemos nossa discussão para as categorias metodológicas de análise da sua textualização: os mecanismos de textualização e os mecanismos enunciativos dos textos.

\subsection{A textualização do gênero}

Podemos afirmar que, para Bronckart (1997; 1999; 2005; 2006), a textualização dos gêneros pode ser caracterizada por mecanismos de textualização e por mecanismos de enunciação.

\subsubsection{Mecanismos de textualização}

Os mecanismos de textualização, segundo modelo proposto por Bronckart (1997; 1999), referem-se aos mecanismos que permitem o desenvolvimento do conteúdo temático e a construção da coerência textual.

São eles: a conexão, a coesão nominal e a coesão verbal. Quanto aos mecanismos de conexão, para o autor, são elementos léxico-gramaticais, tais como: sequenciadores, adjuntos adverbiais, conjunções coordenadas e subordinadas, isto é, recursos da língua que exercem funções no texto com valores temporais, lógicos ou espaciais.

Em relação à coesão nominal, o autor refere-se aos mecanismos que permitem a introdução de informações (argumentos) e a retomada (remissão) dessas informações na progressão textual. São processos como: substituição lexical e pronominal, anáforas (simples e complexas). Sobre a coesão verbal, por sua vez, Cristóvão (2001, p. 70) assim esclarece: "quanto à coesão verbal, Bronckart (1997; 1999) afirma que sua função é também a de ser responsável pela coerência temática do texto. Esse tipo de coerência pode ser explicitado pela escolha dos verbos e de seus tempos verbais."

Assim esclarecidos os mecanismos de textualização, vejamos explicitações sobre os mecanismos enunciativos do texto.

\subsubsection{Mecanismos enunciativos}

Os mecanismos enunciativos, para Bronckart (1997; 1999; 2005), são aqueles processos textuais que contribuem para a construção avaliativa do texto, isto é, aspectos valorativos e de responsabilidade enunciativa dessa avaliação. Para o autor:

Essa instância coletiva está necessariamente implicada no conjunto das operações que sustentam a infra-estrutura e os mecanismos de textualização, intervindo mais diretamente nos mecanismos enunciativos propriamente ditos, no caso, na gestão das vozes e das modalizações. (BRONCKART, 1997; 1999, p. 323). 
A importância de investigação da responsabilidade enunciativa e das avaliações (projeções valorativas) nos gêneros está na compreensão das práticas interativas e das diferentes representações do interlocutor e do outro acionadas nessas situações de interação. Para o autor, essas representações têm caráter dialógico ${ }^{11}$ e consubstanciam a significação do gênero. Ainda, esses mecanismos podes ser gerenciados pela polifonia ${ }^{12}$ (entrecruzamento de discursos no texto) e pela modalização (operadores que funcionam como expressão de comentários ou avaliações sobre o conteúdo temático do texto).

Em suma, como discutido anteriormente, os gêneros de textos são produções verbais sócio-histórico-culturalmente situadas que apresentam caracterizações textuais diversas, em função da diversidade de situações de interação as quais medeiam. Dessa forma, para se estudar os gêneros e sua materialização textual, para o ISD, é preciso investigar não apenas as conjecturas sociais das quais o gênero participa, como, em adição, a constituição textual desse gênero a serviço de seu funcionamento nas mediações das práticas interativas. Direcionemos nossa investigação para a constituição textual do gênero ombudsman, mais particularmente para a análise de sua infraestrutura textual.

\section{ANÁLISE DOS DADOS E DISCUSSÕES}

Esta seção busca apresentar os resultados da análise da infraestrutura textual do gênero ${ }^{13}$ ombudsman e se organiza da seguinte forma: (1) infraestrutura textual: tipo de discurso; sequências textuais; estruturação linguístico-textual típica; e (2) textualização do gênero: estratégias argumentativo-avaliativas construídas por meio de recursos linguísticos tais como: modalizações, marcadores argumentativos, marcadores avaliativos, estratégias/operações argumentativas (ex.: exemplificações, comparações, contrastes, justificativas, enumerações, entre outras).

A partir disso, procuraremos compreender quais os efeitos, mediados pela linguagem, que o produtor busca provocar no interlocutor: verificar como os recursos acima descritos orientam o leitor a determinadas conclusões (argumentativas). Para tanto, recuperaremos as diversas discussões teórico-metodológicas das seções anteriores, inter-relacionando-as com a análise e buscando, nesta confluência, não conclusões estanques, mas aberturas para futuras discussões na área.

\subsection{A infraestrutura textual}

Observamos que o gerenciamento da infraestrutura textual do gênero discursivo ombudsman configura-se a partir de diferentes partes textuais que se inter-relacionam na construção da unidade global do texto:

\footnotetext{
${ }^{11}$ Em concordância com o pensamento de Bakhtin (2003).

12 Diverge do pensamento de Bakhtin.

${ }^{13}$ Como já mencionado anteriormente, as discussões sobre as representações sócio-históricas do gênero (âmbito social do gênero: autoria, interlocutores, mídia, circulação, distribuição, etc.) não serão pontuadas neste trabalho, pois requerem uma investigação mais extensiva. Dedicaremos essa questão para estudos futuros.
} 
(1) apresentação contextual do gênero, o que inclui subpartes, que se destinam a (1.1) apresentar o autor e suas credenciais; (1.2) título e subtítulo;

(2) apresentação temática do gênero, que objetiva orientar o leitor para o horizonte temático do gênero, no caso do corpus em análise, podemos observar que o primeiro parágrafo recorrentemente se destina a isso $(\mathrm{Cf}$. OFSP; OPV) $)^{14}$

(3) seleção e organização global da argumentação, o que inclui subpartes, que se destinam a (3.1) estabelecer a opinião do leitor ou do autor; (3.2) apresentar estratégias argumentativas que subsidiam a argumentação; e (3.3) considerações finais e;

(4) fechamento da coluna, parte que visa a apresentar demais informações sobre o autor, assim como dados para contatos com o jornal e com o autor.

Vejamos como isso funciona a partir da análise baseada no OFSP.

A compreensão sobre a infraestrutura textual do gênero nos direciona a sua significação como unidade global de sentido. É a partir da sua regularidade estrutural que podemos atentar para as características linguístico-discursivas que regularizam a materialização textual do gênero. No caso do ombudsman, o plano geral do texto pode ser caracterizado pelas seguintes partes textuais: (a) contextualização; (b) tematização; (c) argumentação e (d) fechamento. Sob a ótica dessa arquitetônica textual, podemos compreender a organização macrotextual desse gênero e sua significação.

Com base nessa primeira consideração geral sobre a infraestrutura do gênero, podemos afirmar que o tipo de discurso ${ }^{15}$ (Cf. seção 3.1.2) predominante é o tipo interativo. Vejamos:

(1) OFSP - "A morbidez deve ser evitada a todo custo, e o jornal precisa tomar muito cuidado com isso. Não acho que tenha esbarrado nela por enquanto",

(2) OPV - "Sim. É o que tenho a dizer quando hoje entrego aos leitores a última Coluna do meu mandato de ombudsman que chega ao seu término depois de um ano de exercício."

Em ambos os exemplos ( 1 e 2), a marca de $1^{\text {a }}$ pessoa morfologicamente assinalada pelo verbo, não apenas reforça o papel do enunciador, como, em adição, destaca a relação dos participantes da interação. Esse recurso linguístico caracteriza o discurso interativo, posto que, para Machado (2005, p. 244), no tipo interativo, "observamos a presença de

14 As siglas significam: OFSP - Ombudsman publicado na Folha de SP, disponível em: http://www1.folha.uol.com.br/fsp/ombudsma/om0401200901.htm; OPV - Ombudsman publicado no jornal O Povo, disponível em: http://www.opovo.com.br/ombudsman/847643.html.

15 "Quanto à relação entre tipos de discurso e gêneros de texto, embora os autores não a formulem de forma tão explícita [...] parece ser lógico afirmar que, se admitimos que os tipos de discurso estão presentes em qualquer texto e que todo texto se baseia em determinado gênero, eles são também uma das características dos gêneros [...].” (MACHADO, 2005, p. 245). 
formas verbais e de pronomes de $1^{\mathrm{a}}$ e $2^{\mathrm{a}}$ pessoa, que implicam os participantes da interação, o enunciador e o destinatário [...].”.

Quanto à planificação microestrutural e, portanto, relativa às sequências textuais, (Cf. seção 3.1.3), podemos afirmar que no gênero jornalístico ombudsman é predominante a sequência do tipo argumentativo, à medida que esta subsidia as diversas estratégias de argumentação empregadas pelo autor em seu texto. Vejamos como essa sequência funciona como representações de efeitos pretendidos pelo autor.

(3) OFSP - "Não é agradável ver essas cenas. Mas às vezes é indispensável. Quanto à cobertura em palavras do que vem ocorrendo em Gaza, a Folha começou muito mal. No sábado, enquanto os primeiros ataques aéreos ocorriam e prenunciavam o que viria, o jornal circulava com a avaliação de que a expectativa era a de que as tensões arrefecessem depois de Israel ter permitido a chegada de medicamentos e alimentos a Gaza."

(4) OPV - "Penosa porque, no exercício da missão, algumas vezes, temos de criticar publicamente companheiros de trabalho, pessoas com quem havíamos convivido lado ao lado, alguns deles durante muitos anos (no meu caso, mais de três décadas) e com quem estabelecemos laços de estima."

Nos excertos acima (3 e 4), podemos observar que a sequência argumentativa é recorrente para marcar avaliações, validações e modalizações no discurso do autor. Isso se justifica, essencialmente, pelo fato de o gênero ser ancorado por um teor opinativoavaliativo, o que torna frequente o recurso de sequências retórico-argumentativas. Dessa forma, podemos afirmar que, quanto à planificação local da infraestrutura textual do gênero ombudsman, o texto desse gênero se constrói por meio do tipo discursivo interativo e pela sequência do tipo argumentativo.

Em síntese, quanto ao gerenciamento da infraestrutura textual do gênero ombudsman, podemos afirmar que seu texto é organizado a partir de quatro partes constituintes, a nomear, contextualização, tematização, argumentação e fechamento, que se materializam enunciativamente por meio de discurso interativo, que, por sua vez, é construído linguístico-textualmente por meio da sequência textual argumentativa. Esses recursos textuais não apenas regularizam a arquitetônica do texto, como, em adição, o significam nas diversas situações de interação social ${ }^{16}$.

\subsection{A textualização do gênero}

Nesta subseção, procuraremos apresentar como determinados recursos linguísticos operam enunciativamente na constituição e no funcionamento do gênero ombudsman na esfera jornalística. Buscaremos apresentar a identificação e a interpretação dos elementos que regulam os mecanismos de textualização e de enunciação (Cf. seções 3.2.1 e 3.2.2), a nomear, operadores argumentativos, marcadores discursivos, modalizações, índices avaliativos, marcadores de validação discursiva presentes na

\footnotetext{
${ }^{16}$ Conforme resultados do corpus em análise nesta investigação.
} 
construção textual. Comecemos pela discussão dos mecanismos de textualização que operam na infraestrutura textual do gênero ombudsman.

Esses elementos que operam no plano coesivo do texto estão essencialmente saturados de significações e são as ferramentas que dão integibilidade para as estratégias argumentativas. São eles:

(a) Operadores Argumentativos - recursos léxico-gramaticais que orientam argumentativamente o leitor para determinadas conclusões: contraste, comparação, concessão, adição, alternância, entre outras ideias. Por exemplo, em "Não é agradável ver essas cenas. Mas às vezes é indispensável." (OFSP), vemos a idéia de contraste construída pelo operador "mas".

(b) Marcadores Discursivos - recursos linguístico-textuais que se integram ao enunciado, determinando sentidos valorados (concordância, discordância, justificativa, entre outros). Vejamos, por exemplo, um marcador discursivo de (dis)cordância construído por meio da expressão verbal "achar que", no exemplo a seguir:

OFSP - "Não acho que tenha esbarrado nela por enquanto. Imagens fotográficas chocantes podem servir a propósitos humanitários e ajudar a manter vivos na memória coletiva horrores inomináveis e, com isso, dificultar a ocorrência de similares."

(c) Marcas de Discurso Citado - recursos de discurso direto ou indireto que marcam a voz do outro (polifonia) no discurso do autor - "Mas deixo uma frase emblemática que ouvi de meu amigo e memorialista Luís Edgar Cartaxo de Arruda Júnior: "Que o ombudsman jamais perca a capacidade de indignar-se". (OPV).

(d) Índices Avaliativos - adjetivações ou adverbializações que marcam o teor de avaliação/opinião apresentado no texto. Vejamos na afirmação retirada do OFSP - "Não é agradável ver essas cenas. Mas às vezes $\underline{\text { é }}$ indispensável."

(e) Modalizadores - verbos ou expressões modais que norteiam e regulam a significação do discurso: negação, obrigação, possibilidade, probabilidade, entre outros sentidos construídos - "A morbidez deve ser evitada a todo custo, e o jornal precisa tomar muito cuidado com isso. Não acho que tenha esbarrado nela por enquanto." (OFSP).

Em adição, o que percebemos é que os mecanismos de textualização acima descritos funcionam para a construção de mecanismos de enunciação no texto, isto é, para sua construção avaliativo-persuasiva, direcionando o leitor para determinados efeitos de sentido (estratégias argumentativas). Quanto às estratégias de argumentação, ou seja, os efeitos de sentido pretendidos pelo Ombudsman, podemos observar as seguintes:

(a) Estratégia de recuperação de conhecimento prévio do leitor - é uma operação que busca compartilhar com o leitor certos conhecimentos que facilitam ou direcionam a determinados sentidos, sua compreensão do texto. Vejamos no OFSP - "DESDE O CASO da morte de Isabella 
Nardoni, em abril, o ombudsman não recebia tantas mensagens sobre um mesmo assunto numa semana, como nesta, de Ano-Novo, sobre o conflito entre Israel e palestinos."

(b) Estratégia de retomada de assuntos - é uma operação que revisita, dentro do texto, informações já mencionadas antes no mesmo texto ou em outros, criando elos intertextuais. Vejamos no OPV - "O ombudsman, sem nenhum exagero, exerce uma função pública numa empresa privada, $\underline{\text { como }}$ já foi dito antes."

(c) Estratégia de reenunciação do discurso do outro como validação da informação/argumento - é uma operação que recupera o discurso do outro para ser enquadrado no argumento do autor. Vejamos essa operação no OPV - "Dois leitores se queixaram de fotos de crianças mortas. Zuleika Haddad perguntou: "Por que a Folha precisa estampar foto de uma menina de 4 anos em seu funeral?". Geraldo Pietragalla Filho argumentou que as fotos "em nada contribuem para a compreensão dessa guerra insana; são manifestações mórbidas".

(d) Estratégia de avaliação - é uma operação em que, por meio de índices avaliativos, o autor avalia determinadas informações, contribuindo, dessa forma, para a construção e justificativa de sua tese no texto. Vejamos essa estratégia no OFSP - "Eu, no entanto, acredito que, quando o bem-estar da coletividade está em jogo, o ombudsman não só pode, mas deve tomar posicionamento sobre qualquer assunto, cobrando atitudes do jornal e dos jornalistas."

(e) Estratégia de explicação - é uma operação que busca apresentar determinadas explicações para os fatos que estão sendo textualizados no texto. Vejamos no OPV - "Tal prerrogativa está prevista no Regimento do Ombudsman do O POVO, inclusive. Mas esta é opinião individual. Não a estou recomendando para minha sucessora ou meus sucessores."

A breve análise aqui apresentada, seja sobre a infraestrutura textual do gênero, seja sob estratégias e operadores que se articulam para a construção discursiva da argumentação do texto, nos conduz a uma compreensão de como o gênero jornalístico ombudsman funciona. Podemos, sob essa perspectiva, atentar para como os gêneros são materializados textualmente e como os textos, enquanto unidades globais de sentido, são discursivamente orientados para determinados sentidos e não outros.

\section{CONSIDERAÇÕES FINAIS}

Com a investigação sobre o gênero ombudsman, mais especificamente sobre sua infraestrutura avaliativo-persuasiva, podemos entender que esse gênero apresenta tipo de discurso e de sequências textuais típicas, que não apenas caracterizam sua construção argumentativa como, em adição, significam as diferentes avaliações, posições e opiniões que se articulam na textualidade desse gênero na esfera do jornalismo. $O$ tipo de discurso interativo e a sequência textual de ordem argumentativa caracterizam a infraestrutura da amostra analisada, o ombudsman publicado na Folha de S. Paulo (SP) 
em 04 de janeiro de 2009 e o ombudsman publicado dia 03 de janeiro de 2009 pelo jornal $O$ Povo (CE).

O que buscamos neste trabalho foi apresentar uma breve análise da construção textual do gênero ombudsman na esfera jornalística. Percebemos nesta pesquisa, como detalhado acima, que este gênero se constitui por meio do entrecruzamento de diferentes aspectos linguístico-enunciativos de tipos de discurso que se entrelaçam na construção da infraestrutura textual. Assim, esse gênero constrói sentidos avaliativoargumentativos que não apenas direcionam a compreensão leitora como, em adição, saturam esse gênero com diferentes efeitos de sentido.

Cabe ressaltar que o que objetivamos não foi uma análise das regularidades do gênero, o que demandaria um universo de exemplares maior do que o corpus desta presente pesquisa, mas procuramos investigar características típicas do gênero a partir de uma análise textual de um universo de análise particular e situado. Em outras palavras, não buscamos apresentar generalizações, mas buscamos identificar e interpretar especificidades de dois exemplares do gênero quanto a sua arquitetônica textual. Portanto, podemos observar como a relação de mútua constituição entre texto e gênero não apenas colabora para a nossa própria compreensão de como usamos a linguagem, mas, em adição, contribui para o entendimento do porquê usamos a linguagem da forma que a usamos.

\section{REFERÊNCIAS}

ADAM, J.M. Linguistique textualle: Des genres de discours aux textes. Paris: Nathan, 1999.

Les textes types et prototypes - récit, description, argumentation, explication et dialogue. Paris: Nathan, 2001.

BAKHTIN, M. Estética da criação verbal. São Paulo: Martins Fontes, 2003.

BRONCKART, J.P. Atividade de linguagem, textos e discursos. Por um interacionismo sócio-discursivo. São Paulo: Educ, 1999/1997.

2.ed. São Paulo: Educ, 2007.

Restrições e liberdades textuais, inserção social e cidadania. In: Revista da ANPOLL. Campinas/SP. N.19, 2005, pág. 231-256.

- Atividade de linguagem, discurso e desenvolvimento humano. Campinas/SP: Mercado de Letras, 2006.

DOLZ, J; SCHNEUWLY, B. Seqüências didáticas para o oral e a escrita: apresentação de um procedimento. In: Mercado de Letras, 2004. . Gêneros orais e escritos na escola. Campinas, SP: 
CRISTOVÃO, V. L. L. Gêneros e ensino de leitura em LE: os modelos didáticos de gêneros na construção e avaliação de material didático. Tese (Doutorado em Lingüística Aplicada) - Pontifícia Universidade Católica, São Paulo, 2001.

HABERMAS, J. Teoria de la acción comunicativa: racionalidad. de la acción y racionalización social. Madrid: Taurus humanides, 1999.

LEONTIEV, A.N. (1984). Activité, Conscience, Personalité. Moscou: Éditions du Progrès.

MACHADO, A. R. Para (re) pensar o ensino do gênero. Calidoscópio - Revista de Lingüística Aplicada, São Leopoldo, v. 2, n. 1, p.17-28, 2004.

A perspectiva interacionista sociodiscursiva de Bronckart. In: Gêneros: teorias, métodos e debates. J.L. MEURER, A. BONINI \& D.A. MOTTA-ROTH, D. (orgs.), 2005.

MAGALHÃES, Maria Cecilia Camargo; ROJO, Roxane Helena Rodrigues. Classroom interaction and strategic reading development. In: BARBARA, Leila; SCOTT, Mike. Reflections on language learning. Clevedon : Multilingual Matters, 1994. p.75-88.

OLIVEIRA, Marta Kohl de. Vygotsky. Aprendizado e desenvolvimento: um processo sócio-histórico. São Paulo: Scipione. (Série Pensamento e Ação no magistério. Mestres da Educação), 1993.

ROJO, Roxane Helena Rodrigues. Contribuições do pensamento de Vygotskky para a pesquisa (em LA) hoje. In: SMOLKA, Ana Luiza Bustamante (Org.). Centenário do nascimento de Piaget, Freinet, Vygotsky, Jakobson. São Paulo: Unicamp, 1998.

SILVA, C. E.L. Quando é preciso chocar sem morbidez. Folha Online: São Paulo, 04, jan. 2009. Disponível em:

$<$ http://www1.folha.uol.com.br/fsp/ombudsma/om0401200901.htm>. Acesso em 05, jan. 2009.

SCHNEUWLY, Bernard. 1994. Genres et types de discours: considerations psychologiques et ontogénétiques. In: Colloque de l'université Charles-de Gaulle III. Neuchâtel, 1994. Anais... Neuchâtel: Peter Lang, p. 155-173.

VERLAINE, P. Valeu a pena? O Povo Online: Fortaleza, 03, jan. 2009.

Disponível em: < http://www.opovo.com.br/ombudsman/847643.html $>$. Acesso em 05, jan. 2009.

VYGOTSKY, Lev Semenovictch. Pensamento e Linguagem. Trad. Jeferson Luiz Cmaargo. São Paulo: Martins Fontes, 1984.

WERTCH, James V; SMOLKA, Ana Luiza Bustamante. Continuando o diálogo: Vygotsky, Bakhtin e Lotman. In: DANIELS, Harry (Org.) Vygotsky em foco: 
pressupostos e desdobramentos; Trad. Mônica Sady Martins, Elisabeth Jafet Cestari. Campinas: Papirus, 1994. 